\title{
ASSESSMENT OF TECHNIQUE SENSITIVITY AND GINGIVAL HEALTH IN MANAGEMENT OF CERVICAL LESIONS PERFORMED USING SUBGINGIVAL CLAMP VERSUS RETRACTION CORD: A RANDOMIZED CONTROLLED CLINICAL TRIAL
}

\author{
Nada H. Shehab ElDin*, Omar O. Shaalan** and Shereen H. Ibrahim***
}

\begin{abstract}
Aim: the current study was conducted to compare technique sensitivity and gingival health of carious and non-carious cervical lesions performed using subgingival clamps and retraction cords.

Methodology: 24 teeth with carious or non-carious cervical lesions were divided randomly into 2 groups receiving one of the two gingival retraction techniques, either subgingival clamp (KSK clamp \#44) or retraction cord (Ultrapak E), technique sensitivity was evaluated at baseline (before application) and immediately after application while gingival health was evaluated before and immediately after application, 2 weeks, 1 and 4 months. Statistical analysis was done using t-test, Chi-square test, Kruskal-Wallis test and Mann-Whitney test where significance level was set at $P \leq 0.05$.
\end{abstract}

Results: There was a statistical significant difference between retraction cord and subgingival clamp regarding time of application and gingival laceration, where retraction cord took longer application time $(\mathrm{p}=0.01)$ and subgingival clamp showed higher laceration frequency $(\mathrm{P}=0.033)$. Regarding patient satisfaction, isolation from crevicular fluids, need for local anesthesia, pink esthetic score, gingival bleeding and sensitivity, there was no statistical significant difference between both groups.

Conclusion: Technique sensitivity and long term gingival health were the same for both groups except that subgingival clamp provided minimal chairside time and care should be taken upon clamp application to avoid gingival laceration.

KEYWORDS: Cervical lesion, gingival health, retraction cord, subgingival clamp, technique sensitivity.

\footnotetext{
* Internal resident, Conservative Dentistry Department, Faculty of Dentistry, Cairo University, MSc Degree Candidate, Conservative Dentistry Department, Faculty of Dentistry, Cairo University

** Lecturer, Conservative Dentistry Department, Faculty of Dentistry, Cairo University

*** Associate Professor, Conservative Dentistry Department, Faculty of Dentistry, Cairo University
} 


\section{INTRODUCTION}

Modern conservative dentistry is based on two main principles, prevention and aesthetics. Introducing new materials and improved technologies in the dental practice has created new opportunities to achieve these two principles. Cervical lesions either carious or non-carious are a common problem nowadays. They have several reasons to occur, some of these reasons are poor oral hygiene, corrosive food and drinks consumption and finally occlusal stress concentrating factors like occlusal interferences, premature contacts, bruxism, and clenching Perez et al. (2012).(14) Restoring cervical lesion is a challenging procedure in dentistry as they are one of the less durable types of restorations and have a high index of loss of retention, marginal excess and secondary caries. This could be attributed to difficulties in isolation that requires the tooth to be exposed and isolated to achieve accessibility, protecting the surrounding area from harmful effects of the procedure and also the control of the sulcular fluid to allow proper adhesion of the esthetic restoration as the closeness of the gingival crest to cervical lesions makes it hard to remove fluids Yankov et al. (2017). (23)

There are several methods to achieve retraction; retraction cord is the most commonly used method. It controls the soft tissue displacement, gingival bleeding and expose the margins which provide good visualization and access. Retraction cord technique is effective and safe if the gingiva is healthy, also it is an inexpensive retraction method Ashri et al. (2016). ${ }^{(3)}$ However, the use of retraction cord may be time consuming, cause gingival recession after healing and bleeding after removal, its application needs practice and skill as improper handling of the cord can cause traumatic injuries, gingival recession and marginal exposure of the restoration, it may cause postoperative discomfort and pain for the patient and finally leaving the retraction cord for long time or forgetting to remove it from the sulcus can cause permanent damage to the gingival tissue

\section{Rajambigai et al. (2016). ${ }^{(16)}$}

Generally the rationale for conducting the research was that gingival retraction using clamps with rubber dam isolation could be less traumatic to the gingiva, overcome drawbacks of the other retraction methods and allow for better visualization to the cavity margins during the critical restorative procedure. They prevent vertical and horizontal tissue displacement beneath the area of dentogingival attachment caused by retraction cord. Subgingival clamps application technique prevents accidental slippage and trauma to surrounding soft tissue during the restorative procedure. They provide maximum tissue retraction without laceration of gingival tissues. Their availability in different sizes and shapes provide a good adaptation to any tooth configuration and any inaccessible area Liebenberg (1993). ${ }^{(11)}$

Evidence based information is inconclusive in this area, therefore it was found beneficial to evaluate sub-gingival clamp in handling and retracting the gingival tissue at the cervical area to see its effect on the gingival health and its technique sensitivity compared to the most commonly used method (retraction cord), as gingival displacement for cervical restorations affects smile and therefore patient satisfaction. Therefore, the aim of the study is to compare the technique sensitivity and gingival health of carious and non-carious cervical lesions performed using subgingival clamps and retraction cords. The null hypothesis tested is that there is no significant difference in clinical performance between subgingival clamp and retraction cord application on technique sensitivity and gingival health immediately after application, after 2 weeks, 1 and 4 months. 


\section{MATERIALS AND METHODS}

In this randomized controlled clinical trial the variables were two tissue displacement techniques, Ultrapak E retraction cord (sizes: \#0, \#00) (Ultradent, Utah, USA) as a control and KSK subgingival clamp (\#44) (Dentech KSK, Tokyo, Japan) as an intervention. 24 teeth were selected and assigned in two groups after randomization and each group has 12 teeth with cervical lesion according to sample size calculation. Each generated random number represented assigning either intervention or comparator to each patient in a random manner. To ensure the allocation concealment, opaque sealed envelopes were made containing the grouping generated previously and titled by numbers. Patients who met the inclusion criteria were enrolled into the study by the assessors. The operator chose between numbers in an opaque sealed envelope as the randomization codes were not released until the participants had been recruited into the trial. All procedures performed in this study, involving human participants, were in accordance with the ethical standards of Research Ethics Committee of Faculty of Dentistry, Cairo University (CREC), and approval no. 7- 4-19. This randomized controlled clinical study was held in Faculty of Dentistry, Cairo University, Egypt. The assessors and statistician were blinded to the material assignment while the operator and the patient were not due to the difference in material presentation and its application protocol.

\section{Eligibility criteria:}

In order to obtain homogenous participants within the sample size in this trial and to avoid any heterogeneity or limitation, the following inclusion and exclusion criteria were selected.

\subsection{Inclusion criteria of the participants:}

- Subject not less than 18 years and not more than 35 years of age Shamsuzzaman et al. (2013). ${ }^{(20)}$
- Have at least one carious or non-carious cervical lesion Loguercio et al. (2015). ${ }^{(12)}$

- Cervical lesions should be equi-gingival or subgingival.

- Can comply to oral hygiene measures or with good oral hygiene Loguercio et al. (2015). ${ }^{(12)}$

- Have sufficient cognitive ability to understand consent procedures Loguercio et al. (2015)..$^{(12)}$

\subsection{Exclusion criteria of the participants:}

- Patients less than 18 years or more than 35 years old Shamsuzzaman et al. (2013). ${ }^{(20)}$

- Patients with any disabilities (mental health conditions, intellectual disability and physical disabilities).

- Systemic diseases or severe medically compromised (Cardiovascular disorder, diabetes, hypertensive, epileptic) Shamsuzzaman et al. $(2013)^{(20)}$ and Anupam et al. $(2013)^{(2)}$.

- Lack of compliance.

- Gingival hyperplasia or blood disorder Shamsuzzaman et al. (2013). ${ }^{(20)}$

- Attachment loss signs of periodontal disease Shamsuzzaman et al. (2013). (20)

- Patients contra-indicated for rubber dam placement (Asthmatic patient, mouth breather, partially erupted tooth, extremely malposed teeth and latex allergy).

\subsection{Inclusion criteria of the teeth:}

- Cervical carious or non-carious lesions Loguercio et al. (2015). ${ }^{(12)}$

- Vital upper or lower teeth with no signs or symptoms of irreversible pulpitis Anupam et al. (2013). ${ }^{(2)}$

- Clinically healthy gingiva and periodontium 
Shamsuzzaman et al. (2013). ${ }^{(20)}$

- No evidence of attachment loss, bleeding on probing or plaque accumulation Shamsuzzaman et al. (2013). (20)

- Patient with thick gingival biotype.

\subsection{Exclusion criteria of the teeth:}

- Peri-apical pathosis or signs of pulpal posterior or anterior pathology Shamsuzzaman et al. (2013). ${ }^{(20)}$

- Non-vital teeth.

- Endodontically treated teeth.

- Teeth showing mobility or sever periodontal affection Chandra et al. (2016). ${ }^{(4)}$

- Tooth indicated for extraction.

- Patient with thin gingival biotype to exclude the gingival biotype as a confounder that may affect the gingival response.

\section{Interventions:}

Assessment of readings for technique sensitivity and gingival health were conducted before local anesthesia injection administration for cavity preparation. Patients may require local anesthesia before starting cavity preparation, as drilling through dentin might be painful and some of the outcomes to be assessed such as need for local anesthesia, patient satisfaction and sensitivity require the absence of any anesthetizing agent to avoid false readings. Therefore, it was mandatory to apply the retraction technique first to test technique sensitivity, then remove it after the required time according to manufacturer's instructions (in case of retraction cord) to test gingival health. After that local anesthesia was injected and operative and restorative procedures were accomplished. This was beneficial especially in case of equi-gingival or subgingival lesions, as gingival retraction is required to allow proper cavity preparation without compromising the gingiva health.

\subsection{Intervention:}

First, local anesthesia was given where the rubber dam will be stabilized at the most rear tooth away from the tooth of interest in order not to affect the readings. Rubber dam sheet, was applied according to manufacturer's instructions. After positioning and stabilizing the rubber dam, KSK subgingival clamp (\#44), was stabilized in position by pushing it cervically using the clamp forceps until it just exposes the cervical margin of the lesion. Stabilizing the subgingival clamp was important to prevent accidental slippage and trauma during the restorative procedure.

\subsection{Comparator:}

The Ultrapak E retraction cord (sizes: \#0, \#00) along with cotton roll were applied according to manufacturer's instructions. Cotton rolls were applied in the vestibule of the patient and saliva ejectors were used to keep the operative field dry. The cord was chosen large enough to firmly compress into the sulcus and was applied using retraction cord applicator which was slightly angled towards the root to facilitate subgingival placement. The cord was left in the sulcus for 8 minutes, after which it was slowly retrieved and cotton roll was removed. Readings were recorded then local anesthesia were injected to start cavity preparation. After cavity preparation re-application of retraction cord was done for another 8 minutes to regain the gingival retraction effect and ensure moisture control before starting the restorative procedure. Cotton rolls changed frequently during the restorative procedure to ensure dry operative field.

\subsection{Cavity preparation procedure:}

Conservative cavities were prepared using a high-speed hand-piece with air-water spray, tungsten carbide round burs of different diameters and \#330 bur (Mani, Tochigi, Japan). Soft caries was removed using sharp excavator (Dentsply, Konstanz, Germany). The outline of the cavity was 
indicated by the extension of caries, definite walls was formed with round internal line angels and a bevel was done at the enamel margin of the incisal wall at an angel 45 degree to the external surface and to a width of 0.25 to $0.5 \mathrm{~mm}$.

\subsection{Restorative phase:}

The adhesive technique used in this trial was selective enamel etching technique. First, cleaning of the cavity was done using oil free triple way syringe. Then, a surface-conditioning agent caulk tooth conditioner gel (Dentsply, Konstanz, Germany) was applied through syringe to enamel prior to adhesive application. It was left according to manufacturer's instructions for 15 seconds, then was rinsed with water and air stream for 15 second then air dried till the enamel have that dull chalky white appearance. After that prime and bond universal adhesive (Dentsply, Konstanz, Germany) that is characterized by active moisture control and wellbalanced hydrophobic and hydrophilic properties allowing complete coverage and penetration at different moisture levels providing simple adhesive application technique was applied to enamel and dentin using micro brush till it completely wet the surface. Agitation was done for 20 seconds then air thinning was done using gentle stream until a glossy and uniform layer was formed, then light cured for 10 seconds using LED X-Lite II 5W light cure. Finally, incremental packing of nano-ceramic ceram $\mathrm{X}$ sphere TEC composite (Dentsply, Konstanz, Germany) of appropriate shade was done using gold plated composite applicator. The restoration was well adapted to the cavity margins, the excess material was removed and the contour was adjusted to minimize the finishing step near the gingival part.

Immediate finishing and polishing was done using fine taper with round end finishing stone (yellow coded) (Mani, Tochigi, Japan) and no.
1.072 finishing and polishing discs (Tor vm, Moscow, Russia) starting by the blue coded disk till the white one with carful strokes. An explorer was used to ensure that there is no excess material at the gingival part and proper adaptation of the restoration by moving it from the tooth to the restoration and moving it the opposite way to ensure there is no open margins.

\section{Outcome assessment:}

The Technique sensitivity was evaluated immediately after application while the gingival health was evaluated at baseline, immediately after application, 2 weeks, 1 and 4 months. Evaluation was done by two assessors, if both assessors differed in score, they discussed and if they did not agree a third assessor resolved the conflict. To avoid other factors that can affect gingival health, strict oral hygiene measures, tooth paste and soft brush were given to each patient to avoid the use of any hard tooth brush or abrasive containing toothpaste and follow up was done regularly.

\subsection{Primary outcome: Technique sensitivity:}

\section{- Time of application:}

Time required for application was calculated using stopwatch from start of placement till completion Shamsuzzaman et al. (2013). ${ }^{(20)}$

\section{- Need for local anesthesia}

It was a patient self-assessment by the patient for discomfort and pain (Yes/No), subjects were asked if they felt any pressure or pain during the application of the retraction cord or the subgingival clamp that necessitate local anesthesia injection Yun et al. (2018). ${ }^{(24)}$

\section{- Isolation from crevicular fluids}

It was assessed visually using magnifying loups (Yes/No). 


\section{- Patient satisfaction}

Patient general self-satisfaction evaluation regarding retraction technique applied was performed using visual analogue scale (VAS) of $10 \mathrm{~cm}$ line with anchors 'extremely dissatisfied' at $0 \mathrm{~cm}$ and 'extremely satisfied' at $10 \mathrm{~cm}$. Higher scores represent greater patient satisfaction with the retraction technique Malmstrom et al. (2015). ${ }^{(13)}$

\subsection{Secondary outcome: Gingival health:}

\section{- Pink esthetics}

Pink esthetic score (PES) assessed seven variables: mesial papilla, distal papilla, softtissue level, soft tissue contour, alveolar process deficiency, soft-tissue color and texture. Each variable was assessed with a 2-1-0 score, where 2 is the best and 0 is the poorest score. The mesial and distal papilla were assessed for completeness, incompleteness or absence while the other variables were assessed by comparison with a reference tooth like a contralateral or a neighboring tooth Fürhauser et al. (2005). ${ }^{(8)}$

\section{- Gingival bleeding}

It was assessed using score for gingival hemorrhage. It was recorded as follows: The cord was left in the sulcus for 3-8 minutes, then it was slowly retrieved or the clamp is removed with a clamp holder. After which the amount of hemorrhage was recorded in terms of score 0 to 2 .

Score 0: No bleeding on removal.

Score 1: Bleeding controlled with air and water spray within 1 minute.

Score 2: Bleeding not controlled within 1 minute Shamsuzzaman et al. (2013). (20)

Follow up measurement was performed through gentle probing of the gingival crevice. If bleeding occurred within 10 seconds a positive finding was then recorded Rebelo and De Queiroz (2011). ${ }^{(17)}$

\section{- Gingival laceration}

The presence of gingival laceration assessed visually (Yes/No) using magnifying loups Loguercio et al. (2015). ${ }^{(12)}$

\section{- Sensitivity}

A visual analog scale (VAS) was used to assess pain/sensitivity using air-water jet to blast air and water at the subjects tooth for 3 seconds at a distance of $1 \mathrm{~cm}$ from the tooth surface. The response of the subject was recorded using a $10 \mathrm{~cm}$ line with anchors designed as 0: no pain, 2: mild pain, 4: moderate pain, 6: severe pain and 10: worst pain Chowdhary et al. (2019). ${ }^{(6)}$

\section{Statistical analysis:}

Statistical analysis was performed using IBM SPSS Statistics Version 2.1 for Windows. Data was presented as frequencies (n) for categorical data; and mean and standard deviation (SD) for continuous data. Kolmogorov-Smirnov and Shapiro-Wilk tests were used to assess data normality of continuous data. The significance level was set at $\mathrm{P} \leq 0.05$.

For continuous data, Independent Student t-test was performed for intergroup comparisons. For categorical data, Mann-Whitney test was performed for intergroup comparisons and Kruskal-Wallis test was used for multiple comparisons. Chi-square test was used to compare frequency distribution of categorical data. The absolute risk, relative risk and attributable risk (risk difference) of each outcome were calculated.

\section{RESULTS}

Regarding technique sensitivity, Independent Student t-test showed that the application of retraction cord $(44.45 \pm 14.95$ seconds) took statistically significantly longer time than subgingival clamp (18.67 \pm 8.42 seconds) $(\mathrm{P}=0.01)$. Chi-square showed that there was no statistically significant difference in frequency of patients that needed local anesthesia 
and isolation from crevicular fluids between both groups $(\mathrm{P}=0.906)$ and $(\mathrm{P}=0.515)$ respectively. Concerning patient satisfaction, Mann-Whitney test showed that there was no statistically significant difference in VAS scores between subgingival clamp group $(9.00 \pm 1.88)$ and retraction cord group $(8.20 \pm 1.75)(\mathrm{P}=0.1000)$ (Table 1).

Regarding gingival health, Mann-Whitney test showed no statistical significant difference in mean scores of pink esthetic scores between both groups at any time interval $(\mathrm{P}>0.05)$ and there was statistical significant difference with in each group regarding soft tissue contour as shown in Table 2. Also, Mann-Whitney test showed no statistical significant difference that immediately after application (T0), there was no statistically significant difference in gingival bleeding scores between subgingival clamp group $(0.40 \pm 0.51)$ and retraction cord group $(0.30 \pm 0.48)(\mathrm{P}=0.100)$. At 2 weeks $(\mathrm{T} 1), 1$ month
(T2) and 4 months (T3), no gingival bleeding on removal was observed for both groups (score 0) and this was statistical significant within each group as shown in table 3. Chi-square showed that immediately after application (T0), subgingival clamp showed statistically significantly higher frequency of gingival laceration than retraction cord group ( $\mathrm{P}=0.033)$. At 2 weeks (T1), 1 month (T2) and 4 months (T3), no gingival laceration was detected in both groups. Mann-Whitney test showed that there was no statistically significant difference in sensitivity scores between subgingival clamp group and retraction cord group ( $\mathrm{P}=0.563)$ immediately after application (T0) and at 2 weeks $(\mathrm{T} 1)(\mathrm{P}=0.563)$ and $(\mathrm{P}=0.699)$ respectively. At 1 month (T2) and 4 months (T3), no sensitivity was recorded for both groups (score 0 ) but there was statistical significant difference within retraction cord group as shown in Table 3.

TABLE (1) Mean \pm SD, Frequency and P-value for the comparison of technique sensitivity outcomes between intervention groups at $\mathrm{T} 0$.

\begin{tabular}{|c|c|c|c|c|c|}
\hline Outcome & \multicolumn{2}{|c|}{ Subgingival clamp $(n=10)$} & \multicolumn{2}{|c|}{ Retraction cord $(n=10)$} & \\
\hline \multirow{2}{*}{ Time of application (seconds) } & \multicolumn{2}{|c|}{ Mean \pm SD } & \multicolumn{2}{|c|}{ Mean \pm SD } & P-value \\
\hline & \multicolumn{2}{|c|}{$18.67 \pm 8.42$} & \multicolumn{2}{|c|}{$44.45 \pm 14.95$} & $0.001^{*}$ \\
\hline \multirow{2}{*}{ Need for local anesthesia } & Yes & No & Yes & No & P-value \\
\hline & 2 & 8 & 2 & 8 & $0.906 \mathrm{NS}$ \\
\hline \multirow{2}{*}{ Isolation from crevicular fluids } & Yes & No & Yes & No & P-value \\
\hline & 7 & 3 & 6 & 4 & $0.515 \mathrm{NS}$ \\
\hline \multirow{2}{*}{ Patient satisfaction } & \multicolumn{2}{|c|}{$\operatorname{Mean} \pm$ SD } & \multicolumn{2}{|c|}{ Mean \pm SD } & P-value \\
\hline & \multicolumn{2}{|c|}{$9.00 \pm 1.88$} & \multicolumn{2}{|c|}{$8.20 \pm 1.75$} & $0.1000 \mathrm{NS}$ \\
\hline
\end{tabular}


TABLE (2) Mean \pm SD and P-value for the comparison of pink esthetic scores (PES) between intervention groups at each evaluation time.

\begin{tabular}{|c|c|c|c|c|}
\hline \multirow{2}{*}{ Outcome } & \multirow{2}{*}{$\begin{array}{l}\text { Evaluation } \\
\text { time }\end{array}$} & Subgingival clamp & Retraction cord & \multirow{2}{*}{ P-value } \\
\hline & & Mean \pm SD & Mean \pm SD & \\
\hline \multirow{5}{*}{ Mesial papilla } & T0 & $2 \pm 0$ & $2 \pm 0$ & $1.000 \mathrm{NS}$ \\
\hline & T1 & $2 \pm 0$ & $2 \pm 0$ & $1.000 \mathrm{NS}$ \\
\hline & $\mathbf{T 2}$ & $2 \pm 0$ & $2 \pm 0$ & $1.000 \mathrm{NS}$ \\
\hline & T3 & $2 \pm 0$ & $2 \pm 0$ & $1.000 \mathrm{NS}$ \\
\hline & P-value & $1.000 \mathrm{NS}$ & $1.000 \mathrm{NS}$ & \\
\hline \multirow{5}{*}{ Distal papilla } & T0 & $2 \pm 0$ & $2 \pm 0$ & $1.000 \mathrm{NS}$ \\
\hline & T1 & $2 \pm 0$ & $2 \pm 0$ & $1.000 \mathrm{NS}$ \\
\hline & $\mathbf{T} 2$ & $2 \pm 0$ & $2 \pm 0$ & $1.000 \mathrm{NS}$ \\
\hline & T3 & $2 \pm 0$ & $2 \pm 0$ & $1.000 \mathrm{NS}$ \\
\hline & P-value & $1.000 \mathrm{NS}$ & $1.000 \mathrm{NS}$ & \\
\hline \multirow{5}{*}{$\begin{array}{l}\text { Level of soft } \\
\text { tissue margin }\end{array}$} & T0 & $1.90 \pm 0.31^{\mathrm{a}}$ & $1.90 \pm 0.31^{\mathrm{a}}$ & $0.939 \mathrm{NS}$ \\
\hline & T1 & $2 \pm 0^{\mathrm{a}}$ & $2 \pm 0^{\mathrm{a}}$ & $1.000 \mathrm{NS}$ \\
\hline & $\mathbf{T 2}$ & $2 \pm 0^{\mathrm{a}}$ & $2 \pm 0^{\mathrm{a}}$ & $1.000 \mathrm{NS}$ \\
\hline & T3 & $2 \pm 0^{\mathrm{a}}$ & $2 \pm 0^{\mathrm{a}}$ & $1.000 \mathrm{NS}$ \\
\hline & P-value & $0.392 \mathrm{NS}$ & $0.392 \mathrm{NS}$ & \\
\hline \multirow{5}{*}{$\begin{array}{l}\text { Soft tissue } \\
\text { contour }\end{array}$} & T0 & $1.60 \pm 0.51^{\mathrm{b}}$ & $1.70 \pm 0.48^{\mathrm{b}}$ & $0.770 \mathrm{NS}$ \\
\hline & T1 & $1.70 \pm 0.48^{\mathrm{a}}$ & $2 \pm 0^{\mathrm{a}}$ & $0.081 \mathrm{NS}$ \\
\hline & $\mathbf{T 2}$ & $2 \pm 0^{\mathrm{a}}$ & $2 \pm 0^{\mathrm{a}}$ & $1.000 \mathrm{NS}$ \\
\hline & T3 & $2 \pm 0^{\mathrm{a}}$ & $2 \pm 0^{\mathrm{a}}$ & $1.000 \mathrm{NS}$ \\
\hline & P-value & $0.005^{*}$ & $0.023 *$ & \\
\hline \multirow{5}{*}{ Alveolar process } & T0 & $2 \pm 0$ & $2 \pm 0$ & $1.000 \mathrm{NS}$ \\
\hline & T1 & $2 \pm 0$ & $2 \pm 0$ & $1.000 \mathrm{NS}$ \\
\hline & $\mathbf{T} 2$ & $2 \pm 0$ & $2 \pm 0$ & $1.000 \mathrm{NS}$ \\
\hline & T3 & $2 \pm 0$ & $2 \pm 0$ & $1.000 \mathrm{NS}$ \\
\hline & P-value & $1.000 \mathrm{NS}$ & $1.000 \mathrm{NS}$ & \\
\hline \multirow{5}{*}{ Soft tissue color } & T0 & $2 \pm 0$ & $1.70 \pm 0.48^{\mathrm{a}}$ & $0.125 \mathrm{NS}$ \\
\hline & T1 & $2 \pm 0$ & $1.90 \pm 0.31^{\mathrm{a}}$ & $0.292 \mathrm{NS}$ \\
\hline & $\mathbf{T} 2$ & $2 \pm 0$ & $2 \pm 0^{\mathrm{a}}$ & $1.000 \mathrm{NS}$ \\
\hline & T3 & $2 \pm 0$ & $2 \pm 0^{\mathrm{a}}$ & $1.000 \mathrm{NS}$ \\
\hline & P-value & $1.000 \mathrm{NS}$ & $0.103 \mathrm{NS}$ & \\
\hline \multirow{5}{*}{ Soft tissue texture } & T0 & $2 \pm 0$ & $2 \pm 0^{\mathrm{a}}$ & $1.000 \mathrm{NS}$ \\
\hline & $\mathbf{T 1}$ & $2 \pm 0$ & $1.90 \pm 0.31^{\mathrm{a}}$ & $0.292 \mathrm{NS}$ \\
\hline & $\mathbf{T 2}$ & $2 \pm 0$ & $2 \pm 0^{\mathrm{a}}$ & $1.000 \mathrm{NS}$ \\
\hline & T3 & $2 \pm 0$ & $2 \pm 0^{\mathrm{a}}$ & $1.000 \mathrm{NS}$ \\
\hline & P-value & $1.000 \mathrm{NS}$ & $0.392 \mathrm{NS}$ & \\
\hline
\end{tabular}


TABLE (3) Mean \pm SD, Frequency and P-value for the comparison of gingival bleeding, gingival laceration and sensitivity between intervention groups at each evaluation time.

\begin{tabular}{|c|c|c|c|c|c|c|}
\hline Outcome & Evaluation time & \multicolumn{2}{|c|}{ Subgingival clamp $(n=10)$} & \multicolumn{2}{|c|}{ Retraction cord $(n=10)$} & \\
\hline & & \multicolumn{2}{|c|}{ Mean \pm SD } & \multicolumn{2}{|c|}{ Mean \pm SD } & P-value \\
\hline \multirow{5}{*}{$\begin{array}{l}\text { Gingival } \\
\text { bleeding }\end{array}$} & T0 & \multicolumn{2}{|c|}{$0.40 \pm 0.51^{\mathrm{a}}$} & \multicolumn{2}{|c|}{$0.30 \pm 0.48^{\mathrm{a}}$} & $0.770 \mathrm{NS}$ \\
\hline & T1 & \multicolumn{2}{|c|}{$0^{\mathrm{b}}$} & \multicolumn{2}{|c|}{$0^{\mathrm{b}}$} & $1.000 \mathrm{NS}$ \\
\hline & $\mathbf{T 2}$ & \multicolumn{2}{|c|}{$0^{\mathrm{b}}$} & \multicolumn{2}{|c|}{$0^{\mathrm{b}}$} & $1.000 \mathrm{NS}$ \\
\hline & T3 & \multicolumn{2}{|c|}{$0^{\mathrm{b}}$} & \multicolumn{2}{|c|}{$0^{\mathrm{b}}$} & $1.000 \mathrm{NS}$ \\
\hline & P-value & \multicolumn{2}{|c|}{$0.005^{*}$} & \multicolumn{2}{|c|}{$0.032 *$} & \\
\hline & & Yes & No & Yes & No & P-value \\
\hline \multirow{4}{*}{$\begin{array}{l}\text { Gingival } \\
\text { laceration }\end{array}$} & T0 & 4 & 6 & 0 & 10 & $0.033^{*}$ \\
\hline & $\mathbf{T 1}$ & 0 & 10 & 0 & 10 & $1.000 \mathrm{NS}$ \\
\hline & $\mathbf{T 2}$ & 0 & 10 & 0 & 10 & $1.000 \mathrm{NS}$ \\
\hline & \multirow[t]{2}{*}{$\mathbf{T 3}$} & 0 & 10 & 0 & 10 & $1.000 \mathrm{NS}$ \\
\hline & & \multicolumn{2}{|c|}{ Mean \pm SD } & \multicolumn{2}{|c|}{ Mean \pm SD } & $P$-value \\
\hline \multirow{5}{*}{ Sensitivity } & T0 & \multicolumn{2}{|c|}{$0.40 \pm 1.26^{\mathrm{a}}$} & \multicolumn{2}{|c|}{$0.40 \pm 0.84^{\mathrm{a}}$} & $0.563 \mathrm{NS}$ \\
\hline & T1 & \multicolumn{2}{|c|}{$0.40 \pm 0.84^{\mathrm{a}}$} & \multicolumn{2}{|c|}{$0.40 \pm 1.26^{\mathrm{a}}$} & $0.699 \mathrm{NS}$ \\
\hline & T2 & \multicolumn{2}{|c|}{$0^{\mathrm{a}}$} & \multicolumn{2}{|c|}{$0^{\mathrm{b}}$} & $1.000 \mathrm{NS}$ \\
\hline & T3 & \multicolumn{2}{|c|}{$0^{\mathrm{a}}$} & \multicolumn{2}{|c|}{$0^{\mathrm{b}}$} & $1.000 \mathrm{NS}$ \\
\hline & P-value & \multicolumn{2}{|c|}{$0.293 \mathrm{NS}$} & \multicolumn{2}{|c|}{$0.024 *$} & \\
\hline
\end{tabular}

\section{DISCUSSION}

Carious and non-carious cervical lesions (NCCLs) are considered common oral lesions that affect long term dental health. Many patients nowadays demand that their dental restorations resemble natural teeth both functionally and esthetically, which makes these cervical lesions present unique challenges for dentists Loguercio et al. (2015). ${ }^{(12)}$ Establishment of clean tooth surfaces free of any contaminants such as saliva, gingival/ sulcular fluid and blood is mandatory to perform proper adhesive procedure. Otherwise, bonding of restoration to dental structure is jeopardized leading to failure of the restoration Loguercio et al. (2015). ${ }^{(12)}$ Therefore, proper gingival retraction and moisture control are two important factors determining the success or failure of the procedure Shamsuzzaman et al. (2013). ${ }^{(20)}$

According to Perez et al. (2012) $)^{(14)}$, gingival retraction cord, rubber dam clamps and periodontal surgery are the most commonly used methods to manage gingival tissues in terms of gingival retraction, access of the lesion and also moisture control.

The impact of a rubber dam and cotton rolls/ retraction cord isolation on the performance of adhesive restorations is a subject of controversy 
Loguercio et al. (2015). ${ }^{(12)}$ It has been considered for decades that rubber dam is an essential component and the optimal method to isolate a dental operating field in modern adhesive dentistry Perez et al. (2012). ${ }^{(14)}$ Subgingival clamps also prevents accidental slippage, trauma to surrounding soft tissue and provide maximum tissue retraction without laceration during the restorative procedure Liebenberg (1993). ${ }^{(11)}$

Gingival displacement using retraction cord is the most common gingival management technique. It physically pushes the free gingiva away but cannot control crevicular fluid seepage Wang et al. (2019). (21) According to Anupam et al. (2013) ${ }^{(2)}$ Ultrapak from Ultradent retraction system showed significant retraction of gingival sulcular width providing well exposed lesion margin. However, using retraction cord pre-impregnated with vasoconstrictor and a hemostatic agent like Ultrapak $\mathrm{E}$ is better as it provides better control over bleeding Al Hamad et al. (2008). (1)

Evidence based information is inconclusive in this area, although both retraction techniques were used for long time. therefore it was found beneficial to evaluate sub-gingival clamp in handling and retracting the gingival tissue at the cervical area to see its effect on the gingival health and its technique sensitivity compared to the most commonly used method (retraction cord), as gingival displacement for cervical restorations affects smile and therefor patient satisfaction with the result.

The results in the current study showed that the application time of retraction cord was longer than subgingival clamp and this was statistically significant $(\mathrm{P}=0.001)$. The application of retraction clamp in its place to engage the subgingival part of the tooth is not time consuming as many dentists may think. Contrary to the belief that rubber dam application is time consuming procedure, Loguercio et al. (2015) ${ }^{(12)}$ in their study evaluating the influence of isolation method of the operative field on gingival damage, patients' preference and restoration retention in non-carious cervical Lesions showed that the time required for restoring non carious cervical lesion was not affected by the choice of the isolation method. Another study done by Shamsuzzaman et al. (2013) ${ }^{(20)}$ showed that retraction cord takes long time to be applied in the gingival sulcus which was statistically significant increased application time. It was justified that the cord was placed using cord packer which was time consuming.

The results of the current study regarding patients' need for local anesthesia and patient satisfaction showed that there was no statistically significant difference between the intervention and the control group. These findings were in agreement with Khan et al. (2017) ${ }^{(10)}$, where participants found rubber dam a pleasing experience. This was explained as patients feel less stress and fear when experienced dentists apply rubber dam as an isolating method and rubber dam benefits were explained to them prior to the treatment. In addition, using retraction cord with cotton roll isolation was shown to be similar to the use of rubber dam isolation regarding patient's preference Loguercio et al. (2015). ${ }^{(12)}$

On the contrary to our findings, Sarmento et al. $(\text { 2014) })^{(19)}$ found significant difference between conventional (Ultrapak cord) and cordless (Expasyl) gingival displacement techniques regarding patient satisfaction/preference, where patients reported stress with the conventional method. This was explained as the conventional technique is more difficult to be performed as it depends on the operator's skill, consumes much clinical time and leads to bleeding and patient discomfort.

Regarding isolation from cervical fluids, the results of this clinical trial showed that there was no statistically significant difference between both groups. This result coincides with Loguercio et al. $(\mathbf{2 0 1 5})^{(12)}$ in their study, where they stated that although there is a common belief that rubber dam 
is the most effective method to provide a clean and contamination free field, the results of their study did not prove this hypothesis. Moreover, the adhesive performance of resin restoration in non-carious cervical lesions didn't show better clinical results using subgingival clamp and rubber dam isolation after 18 month follow up. While Wang et al. (2019) (21) stated that although displacement by physical pushing the free gingiva away using retraction cord which is the most common gingival displacement method, it cannot control sulcular fluid seepage. Moreover, Wöstmann et al. (2008) ${ }^{(22)}$ stated that pure cotton retraction cords may increase crevicular fluid flow and do not provide optimal isolation, but chemical and chemo-mechanical retraction cords showed significant reduction of the crevicular fluid. This may be due to the presence of Epinephrine which act as a vasoconstrictor and hemostatic agent.

The success of any cervical restorative procedure not only depend on the proper field isolation but also on the gingival health. Proper gingival management to avoid gingival tissue damage like bleeding, laceration or sensitivity is a main concern while choosing the retraction technique.

The results of the current study showed that there was no statistically significant difference in gingival bleeding scores between subgingival clamp group and retraction cord group at any time interval. However, it was found that gingival bleeding score immediately after application was statistically significantly higher than other time intervals within each group. Bleeding immediately after application may be as a result of gingival laceration, forced or wrong application of the retraction technique inducing inflammation and minor destruction at the sulcus lining. It also may be due to difference in gingival biotype among the patients, according to Sarmento et al. (2014) ${ }^{(19)}$ thick gingival biotype is more resilient and resistant to mechanical trauma. Gingival damage caused by isolation methods is reversible and not persistent Loguercio et al. (2015). ${ }^{(12)}$ Moreover, their study showed that less than half of the patients reported pain or discomfort after one week of the procedure indicating fast gingival tissue repair. Researchers found that almost all gingival retraction techniques cause tissue injury which recover after 7 days Wang et al. (2019). (21) This may explain why all cases in both groups showed no gingival bleeding on probing by reaching 2 weeks, indicating gingival healing.

The results of the current study contradicted with Shamsuzzaman et al. (2013)(20) and Wang et al. (2019) ${ }^{(21)}$ where they found high mean hemorrhage score for the medicated retraction cord compared to retraction paste regarding control of post retraction bleeding. They explained that as the cord requires more application time and leads to gingival injury or bleeding especially when beginners perform the procedure.

Regarding gingival laceration, there was no laceration observed in retraction cord group, while subgingival clamp showed 4 lacerations immediately after application and this was statistically significant. In a study done by Loguercio et al. (2015) gingival laceration and bleeding were observed in both subgingival clamp and retraction cord groups but they were more common in subgingival clamp group. However, this made no statistical difference in their study. The higher probability of gingival injury with subgingival clamp may be explained by the sharpness of the clamp and the inability to see the gingival margin masked by the rubber dam but this damage is reversible and non-persistent.

Few subjects experienced sensitivity immediately after restorative procedure in both groups and continued till the second visit, after 2 weeks, but there was no statistical significant difference between both groups. This findings were similar to Loguercio et al. (2015) ${ }^{(12)}$, as they reported no statistical significant difference in sensitivity between these two isolation methods after 1 week. This sensitivity may be as a result of gingival laceration, 
bleeding, inflammation or the restorative procedure done at this critical area near the gingival sulcus.

Pink esthetic score (PES) was found to be a suitable tool for reproducible evaluation of soft tissue around tooth structure Chen et al. $(2018)^{(5)}$ and Fürhauser et al. (2005) ${ }^{(8)}$. Analysis of PES regarding mesial papilla, distal papilla and alveolar process showed that both intervention groups scored 2 at each evaluation time. This may be explained as the lesion and clamp positions were at mid cervical area away from the papilla. Therefore, there was no laceration or inflammation at that area. Moreover, there was no laceration detected in the retraction cord group and no recession was observed in both groups at the labial gingival margin indicating no labial alveolar bone resorption. As gingival recession is defined as the change in the position of the gingival margin in relation to cement enamel junction resulting in root exposure according to Daudt et al. (2013).(7)

Regarding the level of soft tissue margin and soft tissue contour no statistical significant difference between both groups in terms of frequency or the score mean. Subgingival clamp could easily break the superficial connective tissue fibers of the sulcus during its application resulting in change in the tissue marginal level which is temporary Daudt et al. (2013).(7) Also, the downward pushing of the retraction cord can cause slight change in the gingival margin level that returns to normal after the effect of retraction cord disappears.

Concerning soft tissue color and texture, no statistical significant difference between both groups. Minor discrepancy was observed with retraction cord which may be due to the epinephrine impregnated in the cord, where risk of inflammation of gingival cuff, rebound hyperemia and even risk of tissue necrosis are disadvantages to epinephrine Yankov et al. (2017) $)^{(23)}$.
According to present knowledge and the results of the current study, the null hypothesis was accepted for need for local anesthesia, isolation from crevicular fluid, patient satisfaction, pink esthetic score, gingival bleeding and sensitivity where both groups showed similar and statistically non-significant results and it was rejected for time of application and gingival laceration where subgingival clamp showed shorter time of application and higher gingival laceration than retraction cord. The findings of the current study were found to be interesting and counteract many of current believes that should encourage further research and more clinical trial to deeply investigate and widen the search at this area.

\section{CONCLUSIONS}

1. Technique sensitivity of subgingival clamp and retraction cord was similar regarding need for local anesthesia, isolation from crevicular fluid and patient satisfaction. While subgingival clamp provided efficient gingival retraction with minimal chairside time.

2. Long term gingival health and stability of periodontal structure was the same for both groups.

3. Care should be taken while using subgingival clamp to avoid gingival laceration.

\section{RECOMMENDATIONS}

Under the limitation of the current study, further clinical trials with increased sample size are recommended. Moreover, more trials studying the influence of rubber dam application time on technique sensitivity, how long does the retraction cord effect last on gingival tissue and the effect of gingival biotype on tissue response toward subgingival clamp and retraction cord are recommended. 


\section{REFERENCES}

1. Al Hamad, K. Q., Azar, W. Z., Alwaeli, H. A., \& Said, K. N. (2008). A clinical study on the effects of cordless and conventional retraction techniques on the gingival and periodontal health. Journal of clinical periodontology, 35(12), 1053-1058.

2. Anupam, P., Namratha, N., Vibha, S., Anandakrishna, G. N., Shally, K., \& Singh, A. (2013). Efficacy of two gingival retraction systems on lateral gingival displacement: A prospective clinical study. Journal of Oral Biology and Craniofacial Research, 3(2), 68-72.

3. Ashri, N. Y., AlRifaiy, M. Q., \& El Metwally, A. (2016). The effect of gingival retraction cord on periodontal health compared to other gingival retraction procedures: A systematic review. Periodontics Prosthodont, 2(3), 19-28.

4. Chandra, S., Singh, A., Gupta, K. K., Chandra, C., \& Arora, V. (2016). Effect of gingival displacement cord and cordless systems on the closure, displacement, and inflammation of the gingival crevice. The Journal of Prosthetic Dentistry, 115(2), 177-182.

5. Chen, J., Chiang, C., \& Zhang, Y. (2018). Esthetic evaluation of natural teeth in anterior maxilla using the pink and white esthetic scores. Clinical Implant Dentistry and Related Research, 20(5), 770-777.

6. Chowdhary, Z., Gupta, P., Kaur, J., Garg, Y., \& Swarup, N. (2019). Multifaceted assessment of dentine hypersensitivity, evaluation of demographic prevalence along with associated factors: A cross-sectional study. Journal of Indian Society of Periodontology, 23(1), 64-8.

7. Daudt, E., Lopes, G. C., \& Cardoso Vieira, L. C. (2013). Does operatory field isolation influence the performance of direct adhesive restorations? Journal of Adhesive Dentistry, 15(1), 27-32.

8. Fürhauser, R., Florescu, D., Benesch, T., Haas, R., Mailath, G., \& Watzek, G. (2005). Evaluation of soft tissue around single-tooth implant crowns: the pink esthetic score. Clinical oral implants research, 16(6), 639-644.

9. Gilbert GH, Litaker MS, Pihlstrom DJ, Amundson CW, Gordan VV, \& DPBRN Collaborative Group (2010) Rubber dam use during routine operative dentistry procedures: Findings from the Dental PBRN. Operative Dentistry, 35(5), 491-499.

10. Khan, R., Butt, F., Rizwan, F., \& Akram, A. (2017). Perception of rubber dam-a qualitative view. World Journal of Pharmaceutical and Medical Research, 3(1), 5-7.
11. Liebenberg, W. H. (1993). Alternative gingival retraction techniques and isolation of the cervical lesion. The Journal of the American Dental Association, 124(10), 92-102.

12. Loguercio, A. D., Luque-Martinez, I., Lisboa, A. H., Higashi, C., Queiroz, V. O., Rego, R. O., \& Reis, A. (2015). Influence of isolation method of the operative field on gingival damage, patients' preference, and restoration retention in noncarious cervical lesions. Operative dentistry, 40(6), 581-593.

13. Malmstrom, H., Dellanzo-Savu, A., Xiao, J., Feng, C., Jabeen, A., Romero, M., Huang, J., Ren, Y. \& Yunker, M. A. (2015). Success, clinical performance and patient satisfaction of direct fibre-reinforced composite fixed partial dentures-a two-year clinical study. Journal of oral rehabilitation, 42(12), 906-913.

14. Perez, C. D. R., Gonzalez, M. R., Prado, N. A. S., De Miranda, M. S. F., Macêdo, M. D. A., \& Fernandes, B. M. P. (2012). Restoration of noncarious cervical lesions: when, why, and how. International journal of dentistry, 2012(special issue), 1-8.

15. Prasad,A. L., Cumberbatch, M., \& Mohammadnezhad, M. (2018). Experience and Practicality of Rubber Dam Use among Undergraduate Dental Students in Fiji. Journal of Oral Hygiene \& Health, 6(2), 1-5.

16. Rajambigai, M. A., Raja, S. R., Soundar, S. J., \& Kandasamy, M. (2016). Quick, painless, and atraumatic gingival retraction: An overview of advanced materials. Journal of pharmacy \& bioallied sciences, 8(5), 5-7.

17. Rebelo, M. A. B., \& De Queiroz, A. C. (2011). Gingival indices: state of art. Gingival diseases-their aetiology, prevention and treatment. Rijeka, Croatia: Intech

18. Ryan, W., \& O'Connell, A. (2007). The attitudes of undergraduate dental students to the use of the rubber dam. Journal of the irish dental association, 53(2), 87-91.

19. Sarmento, H. R., Leite, F. R. M., Dantas, R. V. F., Ogliari, F. A., Demarco, F. F., \& Faot, F. (2014). A double-blind randomised clinical trial of two techniques for gingival displacement. Journal of oral rehabilitation, 41(4), 306313.

20. Shamsuzzaman, M., Quader, S. M. S., Fatema, S., Gofur, M. A., \& Akter, K. (2013). Effect of gingival retraction cord and retraction paste on gingival tissue in fixed prosthodontics impression. Update Dental College Journal, 3(2), 20-27. 
21. Wang, Y., Fan, F., Li, X., Zhou, Q., He, B., Huang, X., Huang, S. \& Ma, J. (2019). Influence of gingival retraction paste versus cord on periodontal health: a systematic review and meta-analysis. Quintessence International, 50, 234-244.

22. Wöstmann, B., Rehmann, P., \& Balkenhol, M. (2008). Influence of different retraction techniques on crevicular fluid flow. International Journal of Prosthodontics, 21(3), 215-6.
23. Yankov, S., Chuchulska, B., Slavchev, D., Hristov, I., \& Todorov, R. (2017). The place of retraction cords among the tissue displacement methods. Journal of IMAB-Annual Proceeding Scientific Papers, 23(4), 1854-1858.

24. Yun, J., Shim, Y. S., Park, S. Y., \& An, S. Y. (2018). New treatment method for pain and reduction of local local anesthesia use in deep caries. Journal of dental local anesthesia and pain medicine, 18(5), 277-285. 